Presented at and included in the proceedings of the International Mechanical Engineering Congress and Exhibition in Anaheim, CA, November, 1998. ASME RTD Vol. 15, E.J. Wolf, editor.

\title{
EVALUATION OF SERVICE-INDUCED RESIDUAL STRESSES IN RAILROAD COMMUTER CAR WHEELS
}

\author{
Jeff Gordon \\ Jerrel A. Jones \\ US Department of Transportation \\ John A. Volpe National Transportation Systems Center \\ Cambridge, MA 02142 USA \\ A. Benjamin Perlman \\ Department of Mechanical Engineering \\ Tufts University \\ Medford, MA 02155 USA
}

\begin{abstract}
Analyses of the effects of service conditions on the distribution of residual stresses in railroad commuter car wheels are presented. Novel software has been applied to estimate the effects of service conditions on the as-manufactured state of these wheels. Contact loads resulting from wheel and rail interaction and thermal loads from on-tread braking are considered. Results indicate that contact stresses acting alone result in increased net rim hoop compression. However, thermal stresses due to frictional heating reverse the as-manufactured residual compressive state. In particular, high-performance stop braking may result in large net hoop tension in the rim. When contact and thermal loads interact, the effects of braking dominate the process. The presence of tensile residual hoop stress at the wheel tread has been shown to favor the formation and growth of fatigue cracks, threatening the safety of train operations. The paper provides a description of the analytical methodology and results of its application to a representative class of commuter service. Comparisons of the predicted depth of rim stress reversal with the thermal cracking observed in the wheels of this fleet provides confidence in the ability of the technique to assess the likelihood of thermal crack development in other types of commuter operations and in railroad freight service.
\end{abstract}

\section{INTRODUCTION}

In the fall of 1991, inspectors for the Federal Railroad Administration became aware of a widespread epidemic of thermal cracking of the wrought wheels of certain electric multiple unit (EMU) commuter vehicles in the New York City area. Initial studies of the observed cracking indicated that in two cases, brake system maintenance problems resulted in overhang of the brake shoe, and eccentric concentration of the frictional heat generated during braking outboard of the center of the wheel tread. The wheel cracking experienced by the third property was determined to be due to the high-performance braking demands of that particular class of commuter service. In this instance, repeated tread braking from high speed resulted in flash-heating of the tread surface causing reversal of the as-quenched residual compression to tension and subsequent thermal fatigue of a shallow layer of wheel material near the tread surface [1].

Immediate action was taken to limit the operating speed of the affected railroad in order to permit continued service and minimize the threat of catastrophic wheel failure in service. Following the initial investigation, a longer-term research program was developed to determine wheel failure mechanisms from the point of view of performance demands. The plan is outlined in Figure 1.

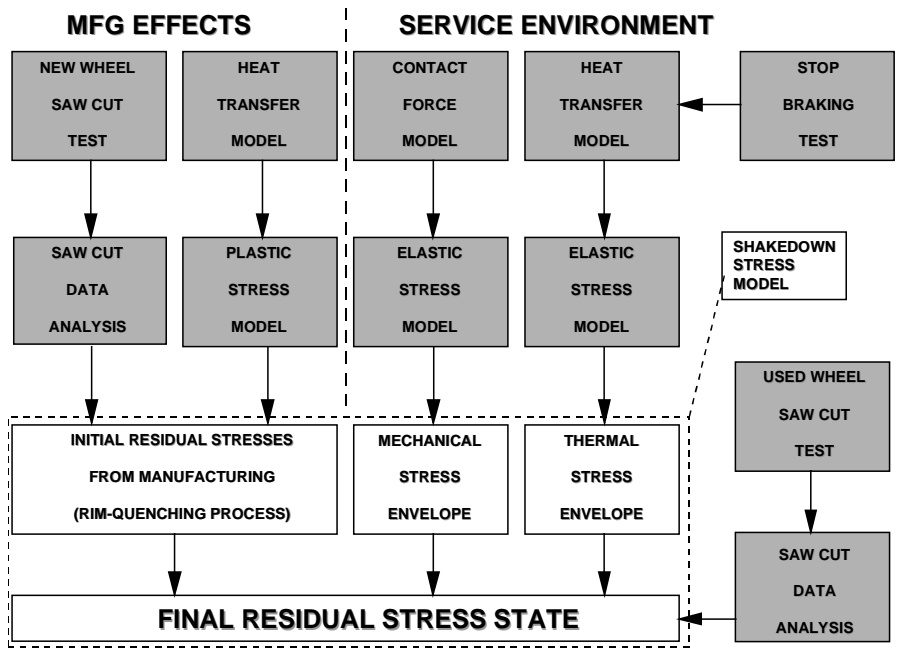

Figure 1. Wheel performance research program. 
As noted in the companion paper, the subject commuter wheels are rim-quenched during manufacture to induce compressive residual circumferential (hoop) stress [2]. This is a desirable feature, as the residual compression near the tread surface will aid in preventing the formation and growth of fatigue cracks in this area. The wheel performance assessment strategy has been designed to determine the effect of service loading (wheel-on-rail contact and thermal loads from braking) on the as-manufactured residual stress distribution, as these stresses have been identified as a reasonable indicator of the likelihood of wheels to experience cracking under operational conditions. This paper will focus on estimating the final residual stress state in commuter wheels due to the combined effects of contact and thermal loading on the initial residual stress distribution present after manufacturing (the unshaded portions of Figure 1). Service conditions are assessed based on the degree of reversal from net rim compression to tension as a result of the imposition of service stresses.

\section{IMPLEMENTATION}

The technique developed for this study consists of a series of analysis steps, each of which will be outlined briefly below. Estimation of the residual stresses due to service loads uses a shakedown stress model which was originally developed for the purpose of determining residual stresses in rail [3]. This method has been modified to accommodate the analysis of wheels and is the cornerstone of the wheel performance study [4]. The shakedown approach uses the elastic stresses due to contact loading and braking, together with the initial conditions (the as-manufactured stress distribution) to approximate the residual stresses which result after repeated loading. Example calculations are presented below in which the effects of contact loading and braking are considered separately. The service conditions are then combined to simulate these effects acting in concert.

\section{MESH DEVELOPMENT}

In order to coordinate the data generated during each of the individual steps in the analysis sequence, the calculation is performed on a computational grid, as depicted in Figures 2 and 3. The mesh was developed from a manufacturer's drawing of the wheel crosssection. The model contains 989 nodes and 907 quadrilateral elements.

\section{QUENCHING SIMULATION}

The residual stress in the 32-inch S-plate commuter wheel has been determined via a finite element simulation of the manufacturing process. The details of this calculation are presented in the companion paper [2]. A non-linear decoupled heat transfer and stress analysis was conducted, following the procedure outlined in [5] with adjustments made to account for the differences between the freight wheel, the object of that study, and the subject passenger wheel. As the hoop stress in the wheel rim is the primary contributor to the formation of thermal cracks, this component will be the focus here. Figure 4 is a contour plot of the residual hoop stress in the wheel rim, representing the initial conditions, upon which the contact and thermal loading will be applied. The lighter contours represent compression, while the darker ones indicate tension. Contour levels are plotted in $\mathrm{MPa}(6.895 \mathrm{MPa}=1 \mathrm{ksi})$. Figure 5 shows the distribution through the rim of the hoop component of residual stress (shown in Figure 4) along the heavy line shown in Figure 3. The vertical axis denotes the depth below the tread surface (in $\mathrm{cm}$ ) and the horizontal axis is the hoop stress (in $\mathrm{MPa}$ ). Figure 5 indicates residual compression to a depth of $3.8 \mathrm{~cm}(1.5 \mathrm{inch})$ and also locates the condemning limit for these wheels (the point to which a wheel may wear before it must be removed from service).

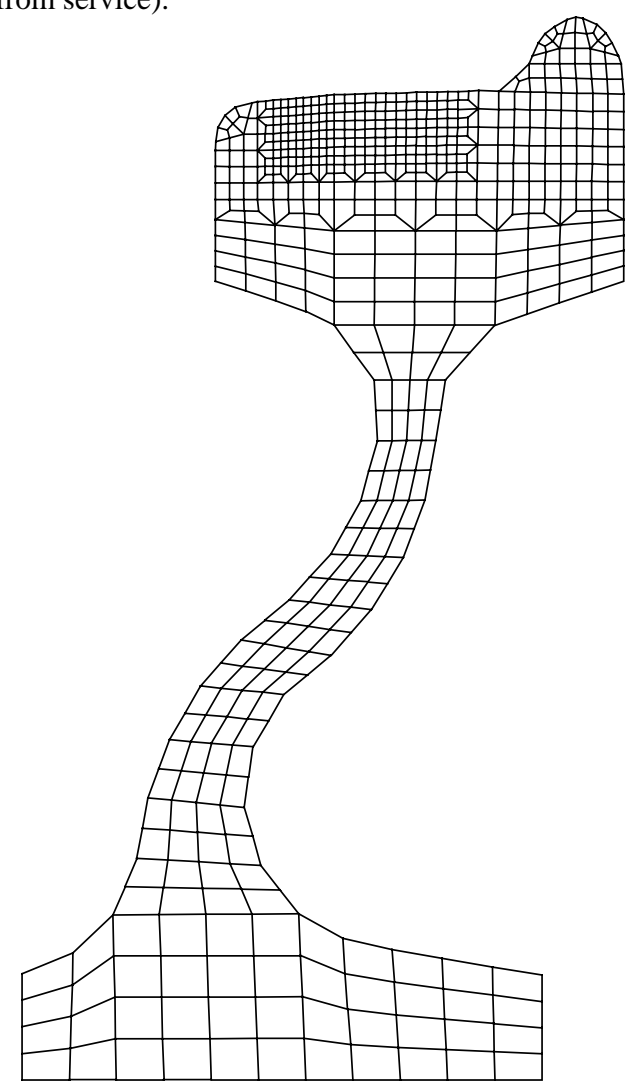

Figure 2. Discretization of 32-inch S-plate wheel.

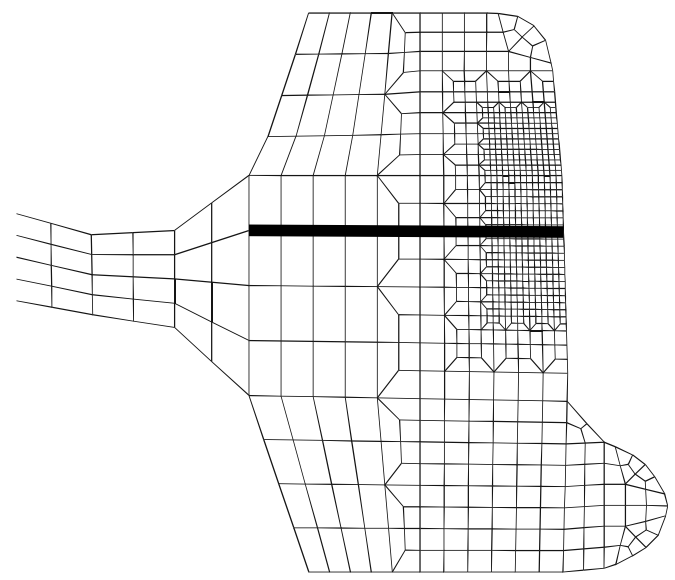

Figure 3. Rim detail. 


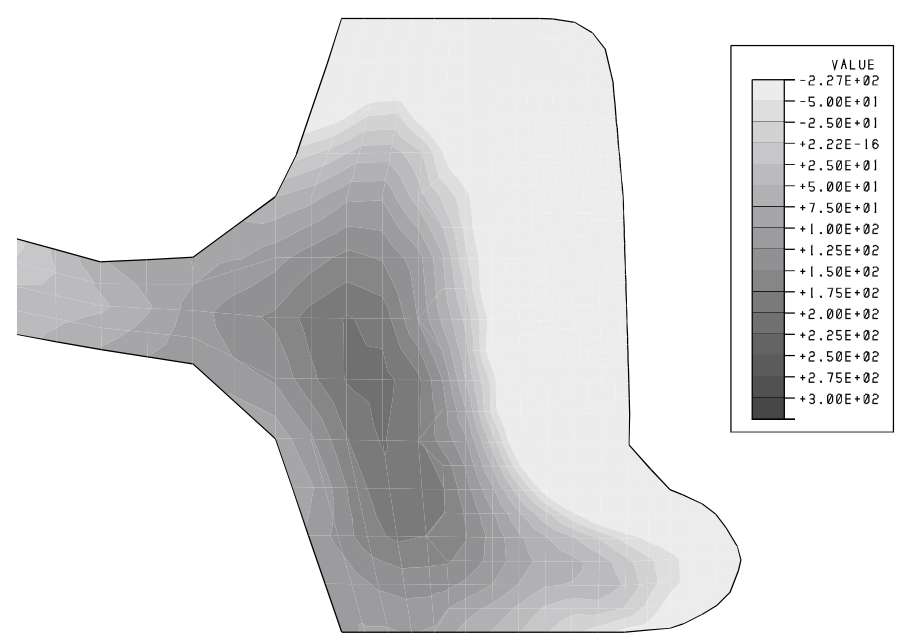

Figure 4. Contours of hoop stress(in MPa) in wheel rim at end of simulated manufacturing process (time $=10$ hours).

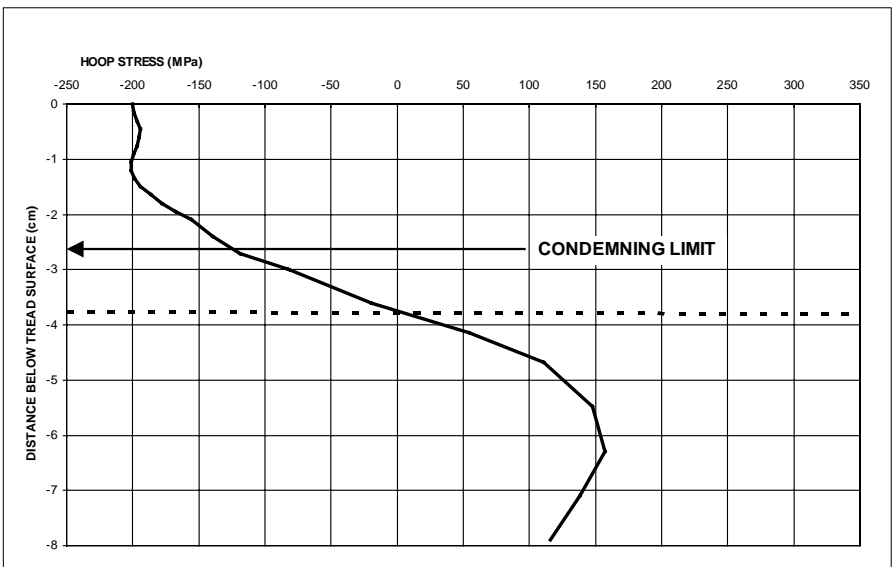

Figure 5. As-manufactured hoop residual stress distribution through rim along heavy line depicted in Figure 3.

\section{WHEEL-ON-RAIL CONTACT SIMULATION}

Next, the elastic stresses due to contact between the wheel and the running rail are determined. The vehicle is assumed to weigh 623 $\mathrm{kN}(140,000 \mathrm{lbs})$ which implies a static wheel load of $78 \mathrm{kN}(17,500$ lbs) applied to the $132 \mathrm{RE}$ rail. As this study is concerned with the stresses in the wheel rim in the vicinity of the center of the tread (where the thermal cracking is observed to occur) candidate contact locations have been selected in that region. These points have been chosen as shown in Figure 6 and do not imply the sole locations at which wheel and rail contact are possible.

For each position, the dimensions of the contact patch at the interface are determined using the technique described in [6]. The dimensions of the elliptical patch are mapped onto a rectangle of sufficient size to produce a bi-parabolic pressure distribution with the same maximum pressure. The pressure distribution is applied to the wheel and the elastic contact stresses are determined by means of Fourier series expansion. The shakedown model is employed to estimate the residual stresses (those stresses remaining after the contact load is removed) corresponding to the imposed elastic stresses in the presence of the manufacturing stresses. This new distribution represents the initial condition prior to application of the next load. The process continues in the same fashion until all contact loads have been applied. The shakedown technique produces results which are independent of the order in which the contact loads are imposed.

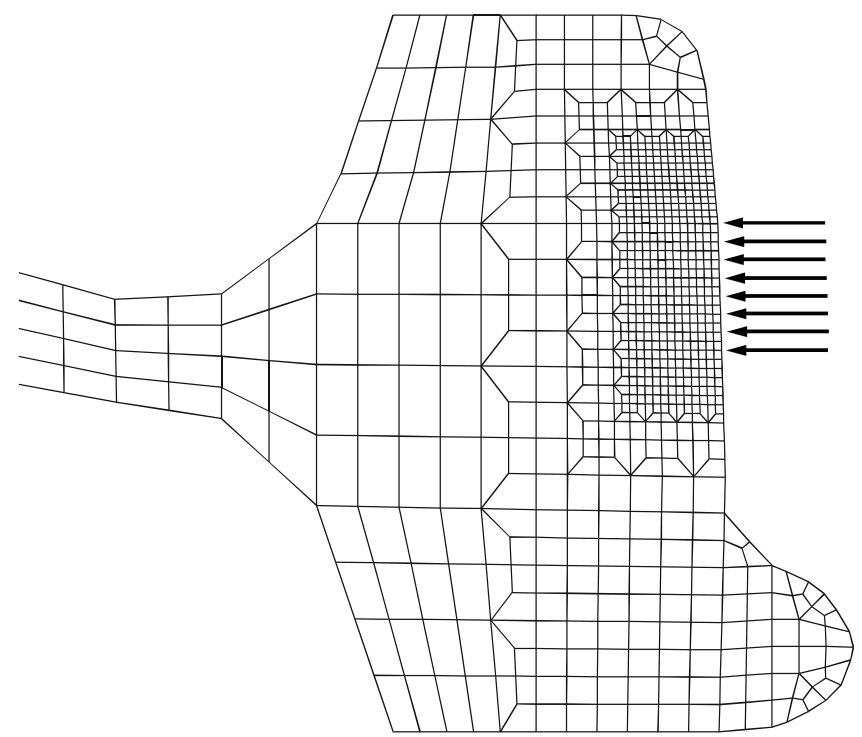

Figure 6. Contact locations.

Results of the contact simulation are shown in Figure 7, which is a plot of the hoop stress along the line through the rim highlighted in Figure 3. The dashed curve in Figure 7 represents the asmanufactured condition (the data from Figure 5), and the solid line shows how this state is changed when contact loads are imposed. The effect of contact is limited to a rather shallow region near the tread surface and results in a net increase in residual compression in that area. From the point of view of fatigue, this increase will serve to further inhibit crack growth.

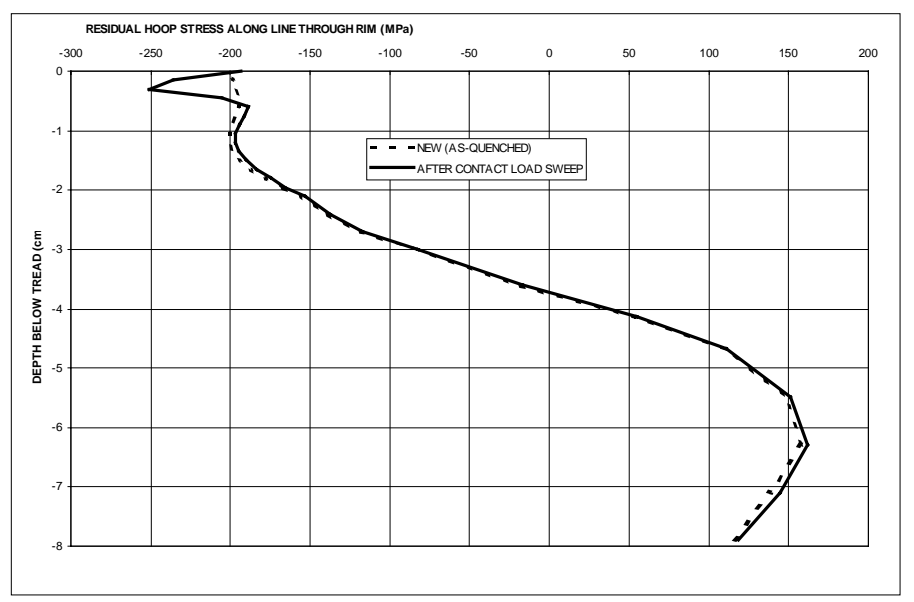

Figure 7. Effect of contact loading on as-manufactured hoop stress distribution in wheel rim. 


\section{BRAKING SIMULATION}

The braking simulation requires investigation of the thermal input to the wheel due to frictional heating to assess the effects of thermal loads on the as-manufactured residual stresses in the rim. The goal of this analysis is to obtain the elastic stresses in the rim due to the thermal gradients induced by heating during on-tread braking, and is conducted in much the same way as the manufacturing process simulation, in that the heat transfer and mechanical calculations are conducted separately.

The heat flux generated at the brake shoe is determined from data obtained from the transit authority regarding the performance characteristics of the EMU vehicles which operate at $160 \mathrm{kph}(100$ $\mathrm{mph})$ and are service braked at a rate of 0.8 to $0.9 \mathrm{~m} / \mathrm{s}^{2}(1.7$ to 2 $\mathrm{mph} / \mathrm{s}$ ). This information is translated into effective retarding force per wheel, which is then expressed in terms of brake power. Figure 8 is a plot of the heat flux (in $\mathrm{MW} / \mathrm{m}^{2}$ ) generated at the wheel tread/brake shoe interface during a service stop from $160 \mathrm{kph}(100$ $\mathrm{mph}$ ). The Figure also contains the same data for a stop from $128 \mathrm{kph}$ (80 $\mathrm{mph}$ ) for comparison (dashed curve). The instantaneous brake power at the start of the braking event is $0.24 \mathrm{MW}$ (320 hp) for 160 $\mathrm{kph}(100 \mathrm{mph})$ operation and $0.22 \mathrm{MW}(290 \mathrm{hp})$ at $128 \mathrm{kph}(80 \mathrm{mph})$.

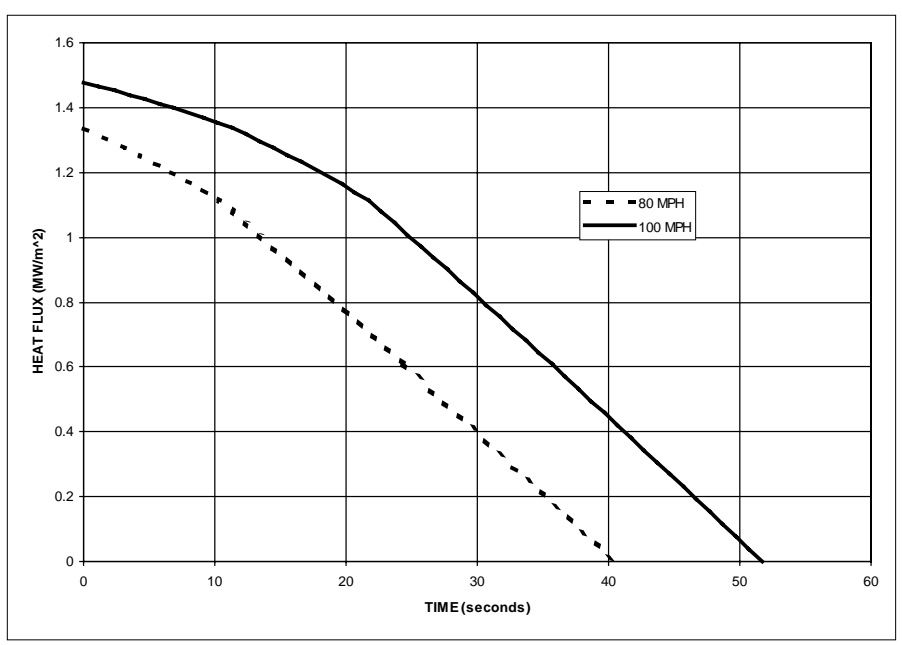

Figure 8. Heat flux at brake shoe during service stops from $160 \mathrm{kph}$ and $128 \mathrm{kph}$ (100 mph and $80 \mathrm{mph}$ ).

The heat flux is applied to the wheel rim at the tread surface over the region between the arrowheads in Figure 9, which represents the width of the brake shoe. It is assumed that $95 \%$ of the generated heat is conduced into the wheel with the remaining $5 \%$ being lost to the surroundings [7]. The heat transfer and elastic stress analyses are conducted using the public domain software TOPAZ2D [8] and NIKE2D [9] from the Lawrence Livermore National Laboratory. The material properties used are listed in Tables 1 and 2 [10]. The procedure developed for executing these analyses is described in detail in [11].

Results of the braking simulation are presented in Figure 10 which illustrates the tread temperature and the values of the hoop and Mises effective stress in an element at the tread surface during the

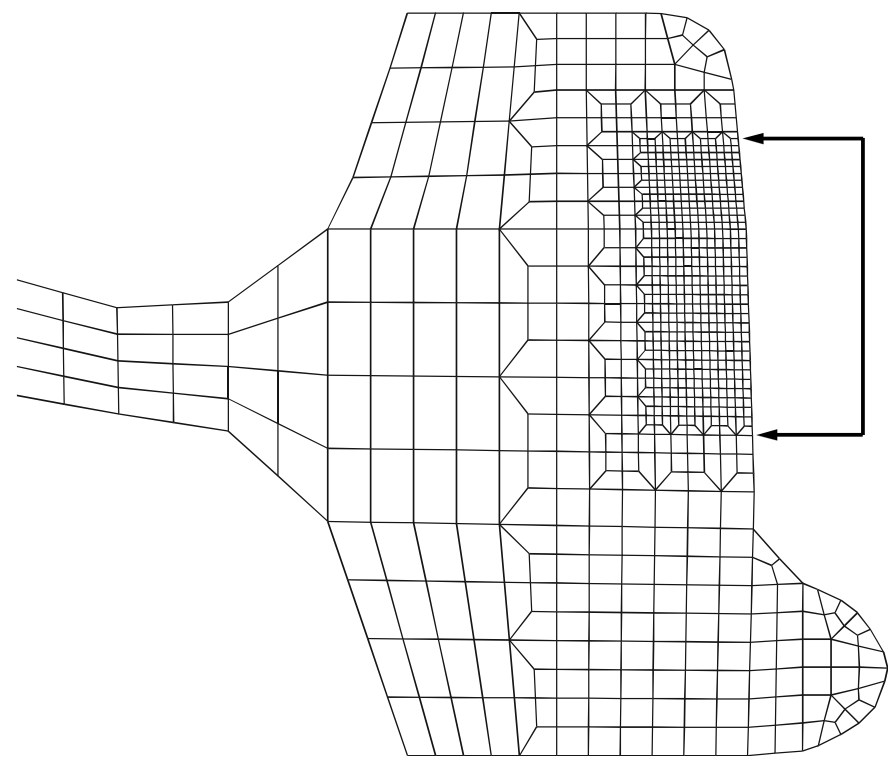

Figure 9. Region of tread surface exposed to braking heat flux.

Table 1. Material properties for heat transfer analysis.

\begin{tabular}{|c|c|c|}
\hline $\begin{array}{c}\text { Temperature } \\
\left({ }^{\circ} \mathrm{C}\right)\end{array}$ & $\begin{array}{c}\text { Specific Heat } c_{p} \\
\left(\mathrm{~J} / \mathrm{kg} \mathrm{K} \text { or }{ }^{\circ} \mathrm{C}\right)\end{array}$ & $\begin{array}{c}\text { Thermal Conductivity } \lambda \\
\left(\mathrm{W} / \mathrm{m} \mathrm{K} \text { or }{ }^{\circ} \mathrm{C}\right)\end{array}$ \\
\hline 0 & 419.5 & 59.71 \\
\hline 350 & 629.5 & 40.88 \\
\hline 703 & 744.5 & 30.21 \\
\hline 704 & 652.9 & 30.18 \\
\hline 710 & 653.2 & 30.00 \\
\hline 800 & 657.7 & 25.00 \\
\hline 950 & 665.2 & 27.05 \\
\hline 1200 & 677.3 & 30.46 \\
\hline
\end{tabular}

Table 2. Material properties for stress analysis.

\begin{tabular}{|c|c|c|c|c|c|c|}
\hline $\begin{array}{c}\text { Temp. } \\
\left({ }^{\circ} \mathrm{C}\right)\end{array}$ & $\begin{array}{c}\text { Young's } \\
\text { Modulus }\end{array}$ & $\begin{array}{c}\text { Poisson's } \\
\text { Ratio }\end{array}$ & \multicolumn{2}{|c|}{$\begin{array}{c}\text { Secant CTE } \alpha_{s} \\
\times 10^{-5} \text { at } \mathrm{T}_{\text {ref }}\end{array}$} & $\begin{array}{c}\text { Yield } \\
\text { Strength }\end{array}$ & $\begin{array}{c}\text { Tangent } \\
\text { Modulus }\end{array}$ \\
\cline { 5 - 6 } & $E(\mathrm{MPa})$ & $v$ & $27^{\circ} \mathrm{C}$ & $871^{\circ} \mathrm{C}$ & $\sigma_{Y S}(\mathrm{MPa})$ & $E^{p}(\mathrm{MPa})$ \\
\hline 24 & 213 & 0.295 & 5.36 & 9.89 & 422.9 & 21.66 \\
\hline 230 & 201 & 0.307 & 7.11 & 10.82 & 424.7 & 25.73 \\
\hline 358 & 193 & 0.314 & 8.05 & 11.15 & 366.7 & 20.29 \\
\hline 452 & 172 & 0.320 & 8.61 & 11.27 & 291.0 & 14.89 \\
\hline 567 & 102 & 0.326 & 9.16 & 11.31 & 132.3 & 5.93 \\
\hline 704 & 50 & 0.334 & 9.60 & 11.28 & 39.4 & 0.92 \\
\hline 900 & 43 & 0.345 & 9.97 & 11.25 & 11.7 & 0.085 \\
\hline
\end{tabular}


braking event. This information is used to select eight intervals over which to execute the shakedown analysis. The intervals are shown as vertical dashed lines in Figure 10.

The intervals are selected such that the first one corresponds to the time at which the yielding begins at the tread surface. This point is determined by comparing the predicted Von Mises effective stress to the value of the yield strength at the surface, taking the reduction in strength due to temperature into account. The final interval is selected at some point shortly after the temperature at the tread surface begins to decrease. At this point further heating of the rim ceases (that is, the material properties degrade no further). The intermediate intervals are more or less evenly spaced in time between the first and last interval.

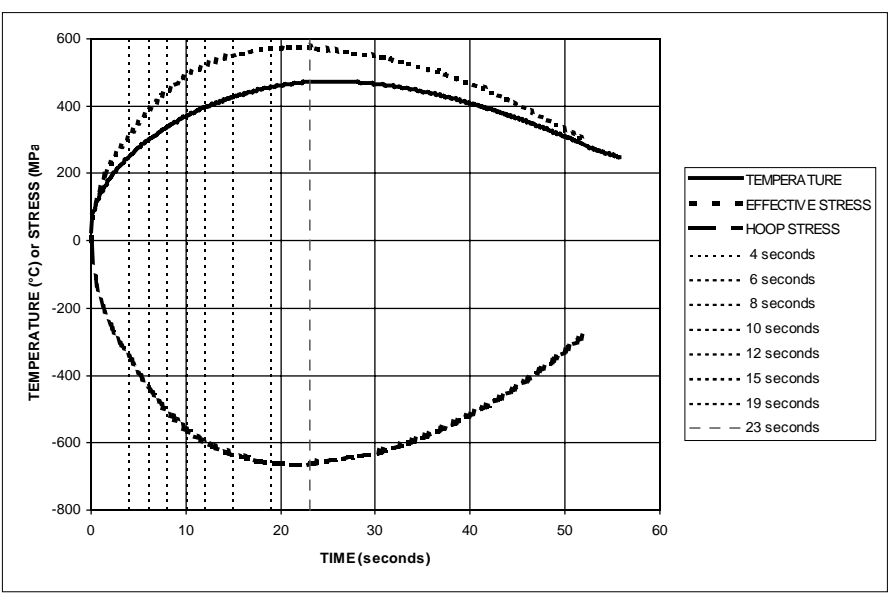

Figure 10. Time history of tread temperature, hoop and Von Mises effective stress during stop from $160 \mathrm{kph}(100 \mathrm{mph})$.

For each time increment, the nodal temperatures are calculated and used to determine local values of the material properties throughout the model. Elastic thermal stresses resulting from the transient temperature distributions are determined for each interval and are applied in the same manner as the contact loads in the preceding section. The as-manufactured condition (Figure 4) represents the initial condition. The shakedown model is invoked and the incremental braking loads are applied (one at a time) with the residual stress distribution predicted for the first one becoming the initial condition for application of the next one, and so on. This process continues until the thermal stresses from each interval have been applied. As opposed to the contact calculations, which are sequenceindependent, the braking simulation must be executed in "chronological" order, to properly account for the degradation of the material properties with temperature.

The results of this sequence are shown in Figure 11 which illustrates the hoop residual stress in the rim along the line depicted in Figure 3 for each of the eight intervals during the braking event. The heavy dashed curve represents the as-manufactured condition (the same as Figure 5). Each of the lighter curves represent one of the eight intervals during the stop at which the residual stresses are calculated. It is clear from this Figure that the extreme temperatures induced in the rim during braking cause sufficiently large thermal stresses to reverse the as-manufactured rim compression into tension. Prior to braking, the hoop compression at the tread surface is on the order of $200 \mathrm{MPa}(29 \mathrm{ksi}$ ). After the simulated braking cycle the hoop stress at the surface becomes tensile with a magnitude of $315 \mathrm{MPa}$ (46 ksi).

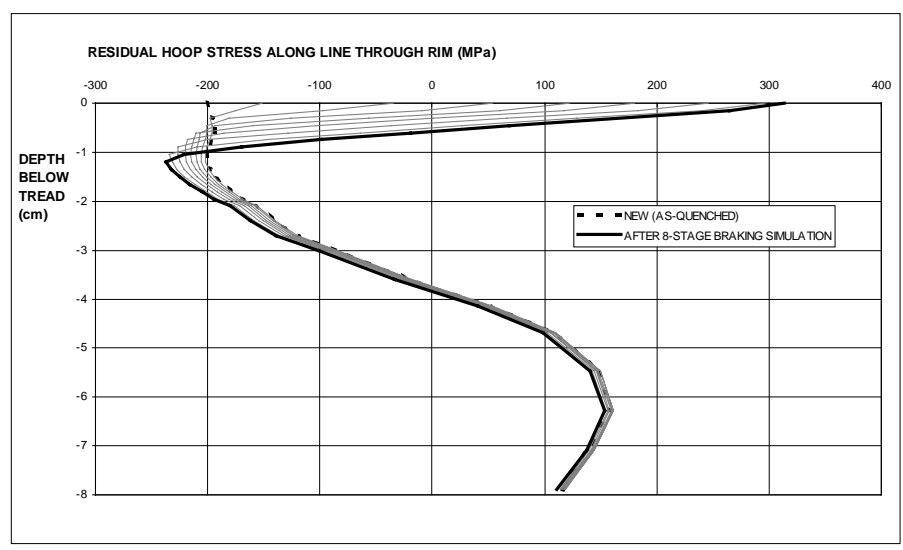

Figure 11. Hoop stress in wheel rim along line depicted in Figure 3 after simulated stop braking from $160 \mathrm{kph}(100 \mathrm{mph})$.

\section{COMBINATION ANALYSIS}

Figures 7 and 11 represent the effects of contact and braking loads, considered separately, on the as-manufactured residual stress in the wheel rim. In reality, however, the subject wheels are exposed to these loading conditions simultaneously. The shakedown software has been designed to accommodate both types of elastic loading acting together. To illustrate this application, additional calculations have been performed to estimate the degree of rim stress reversal under such combined loading.

Figure 12 illustrates the results of two sets of analyses in which contact and braking stresses are applied in tandem and the initial conditions correspond to the as-manufactured state shown in Figure 4. The process described above is repeated for simulated service stops from $160 \mathrm{kph}$ and $128 \mathrm{kph}(100 \mathrm{mph}$ and $80 \mathrm{mph})$ with contact loads applied. The $128 \mathrm{kph}(80 \mathrm{mph})$ analysis was conducted to determine the effectiveness of the proposed remedial action (reduction of the maximum operating speed from 160 to $128 \mathrm{kph}$ ) which was suggested following the initial investigation when the cracking epidemic was discovered. The curve with symbols in Figure 12 is the as-quenched condition (a "new" wheel, Figure 5). The solid curve represents the hoop stress distribution which remains in wheels which are operated at $160 \mathrm{kph}$, and the dashed curve is the result for the same analysis at the reduced operating speed.

In the $160 \mathrm{kph}(100 \mathrm{mph})$ case, the as-manufactured residual compression (200 Mpa; $29 \mathrm{ksi}$ ) is reversed to nearly $350 \mathrm{MPa}(51 \mathrm{ksi})$ at the tread surface. The depth of the tensile layer is about $0.6 \mathrm{~cm}$ (0.24 inch). This is an extremely encouraging finding, considering Figure 13 which illustrates the appearance of the observed thermal defects as a series of axially-oriented cracks originating at the tread surface. Figure 14 shows the profiles of two cracks which were 


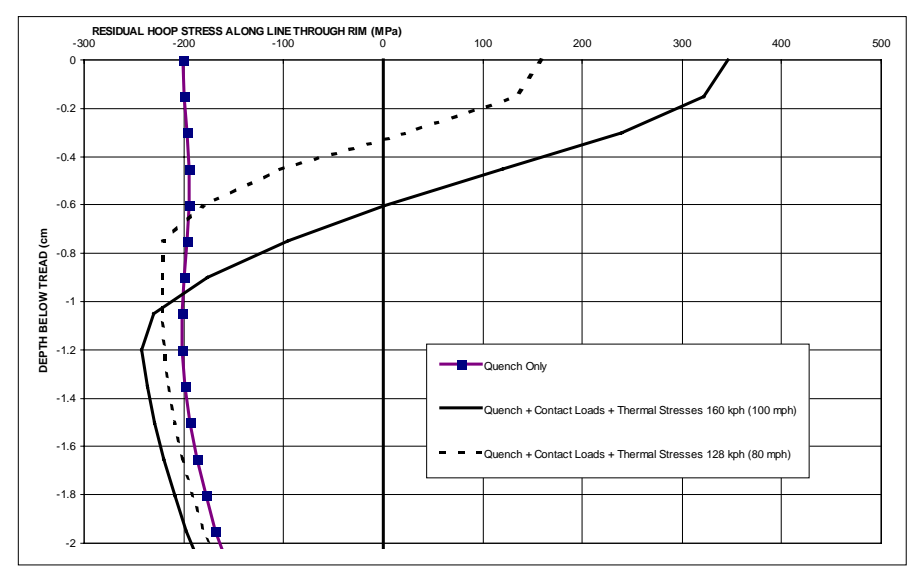

Figure 12. Predicted rim stress reversal under combined contact and thermal loading for simulated stops from $160 \mathrm{kph}$ and $128 \mathrm{kph}$.

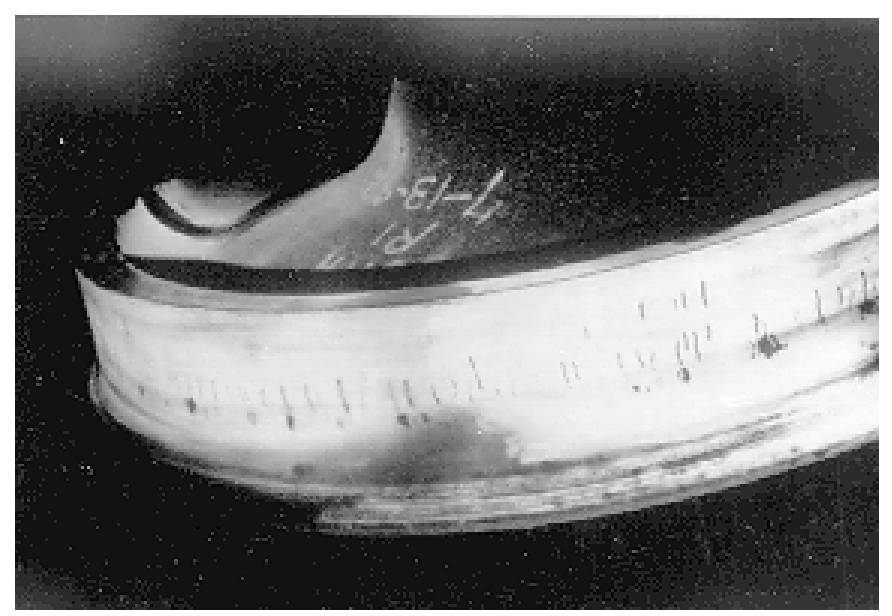

Figure 13. Thermal cracks on commuter wheel tread.

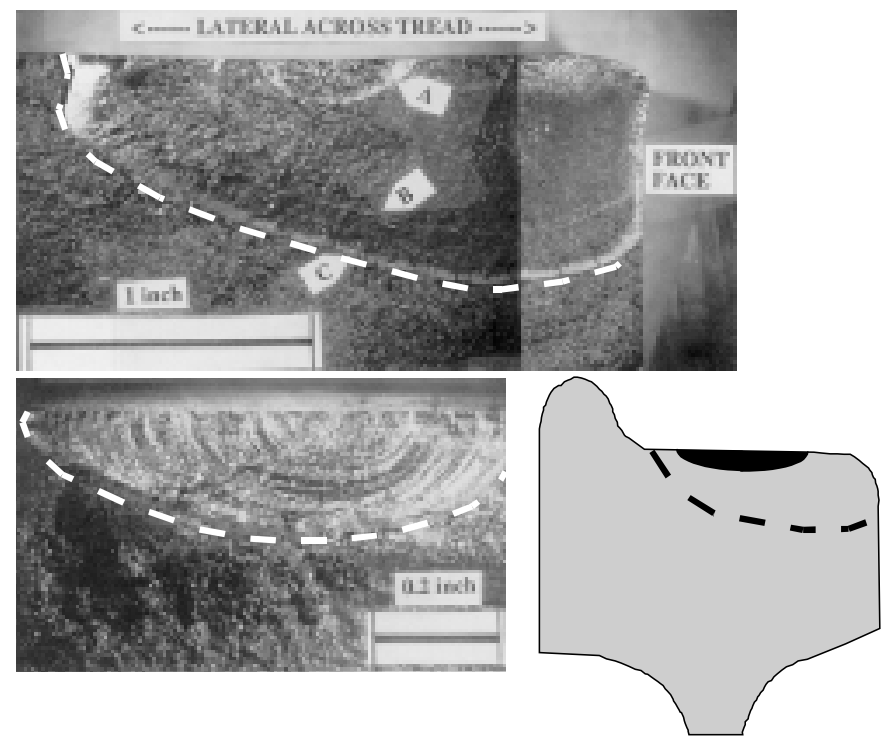

Figure 14. Fatigue crack profile.

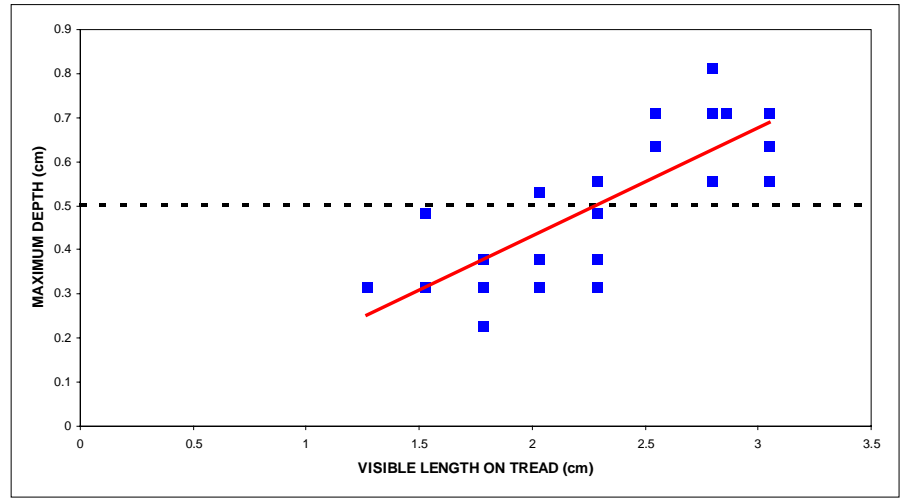

Figure 15. Results of thermal crack size survey.

broken open to reveal features of the fracture surfaces. The characteristic beachmarks in Figure 14 confirm fatigue as the failure mechanism. Figure 15 represents the results of a survey of several cracks found in these wheels during the preliminary investigations [1]. The visible length on the tread surface of approximately 25 cracks was measured. Next, material was milled away until the cracks were no longer visible. In this way, the depth of each crack was inferred. Figure 15 is a cross-plot of the visible length on the surface and the corresponding depth into the rim (in $\mathrm{cm}$ ) for each crack in the survey. The solid line is a linear fit to the data points and the horizontal dashed line represents the average depth of the cracks in the study $(0.503 \mathrm{~cm}$ or $0.2 \mathrm{inch})$.

The agreement between the predicted depth of rim stress reversal $(0.6 \mathrm{~cm})$ and the average measured depth of the thermal cracks $(0.503$ $\mathrm{cm})$ lends credibility to the analytical approach. It is reasonable to assume that the calculation procedure would predict more or less "average" values, since the parameters used in the analysis represent average material properties and average loading (that is, all wheels provide equal braking effort and all wheels experience the same magnitude of contact loading). It is well-known that these assumptions are not valid since the braking effort from wheel to wheel in a given consist can vary, and dynamic effects over the length of a train can result in similar variations in contact load intensity.

Figure 12 includes the results of the assessment of the remedial action plan which temporarily reduced the maximum operating speed to $128 \mathrm{kph}(80 \mathrm{mph})$ until a permanent solution to the cracking problem could be found. The dashed curve in Figure 12 shows a 50\% reduction in the magnitude of the rim surface tension (from $350 \mathrm{MPa}$ to $161 \mathrm{MPa})$ for simulated operation at $128 \mathrm{kph}(80 \mathrm{mph})$ and a similar reduction in the depth of stress reversal (from $0.6 \mathrm{~cm}$ to 0.33 $\mathrm{cm})$. This depth corresponds to the extreme low end of the observed cracking and implies that operation at the reduced speed may reduce the threat of thermal crack formation.

\section{CONCLUSIONS}

The initial results of a multi-step analysis designed to estimate the effects of service loading on the as-manufactured residual stress distribution in commuter car wheels is presented. The goal of the 
work is to determine the degree of rim stress reversal from the "new" condition (net residual hoop compression) to tension at the tread surface due to the imposition of contact loads and thermal stresses from on-tread braking.

A comparison that accounts for the effect of maximum operating speed is presented to illustrate how the methodology can be applied to actual service conditions. The results of the study indicate that for the type of operation considered here, the maximum as-manufactured compressive condition in the rim $(-200 \mathrm{MPa}$ [-29 ksi]) is reversed to $+350 \mathrm{MPa}(+51 \mathrm{ksi})$ maximum hoop tension. The predicted depth of the tensile layer, estimated to be between 0.5 and $0.6 \mathrm{~cm}(0.20$ and 0.24 inch), agrees very well with the depth of thermal cracking observed on wheels in this class of commuter service operated at these speeds.

Future work in this area will include extension of this analytical technique to the study of other types of commuter operations (different vehicles, braking rates, etc.) and eventually to freight service which, while not subjected to the high-performance braking demands present in commuter operations, are frequently exposed to long-term drag braking which can have similar effects on the condition of these wheels.

\section{ACKNOWLEDGMENT}

The work reported in this paper was carried out under the Rail Equipment Safety program sponsored by the Office of Research and Development, Federal Railroad Administration, under the direction of Ms. Claire L. Orth, Chief, Equipment and Operating Practices Research Division. Ms. Monique Stewart is the Project Manager for the work related to railroad wheels.

\section{REFERENCES}

[1] Orringer, O., Gray, D.E. and McCown, R.J., "Evaluation of Immediate Actions Taken to Deal with Cracking Problems in Wheels of Rail Commuter Cars," Final Report, July, 1993. Report No. DOT/FRA/ORD-93/15.

[2] Gordon, J., Perlman, A.B., "Estimation of Residual Stresses in Railroad Commuter Car Wheels Following Manufacture," ASME IMECE RTD, November 1998 (in these proceedings).

[3] Orkisz, J., Orringer, O., Holowinski, M., Pazdanowski, M. and Cecot, W., "Discrete Analysis of Actual Residual Stresses from Cyclic Loadings," Computers \& Structures 35 (4), 1990, pp. 397 412.

[4] Holowinski, M. and Bobrov, E.S., "Estimation of Actual Residual Stresses Due to Braking and Contact Loading of Rail Vehicle Wheels," Francis Bitter National Magnet Laboratory, MIT, March, 1996. Report No. DOT/FRA/ORD-96/02.

[5] Kuhlman, C., Sehitoglu, H. and Gallagher, M., "The Significance of Material Properties on Stresses Developed During Quenching of Railroad Wheels," Proc. Joint ASME/IEEE Railroad Conference, April, 1988, pp. 55-63.

[6] Imtiaz-ul-Haque, Jara-Almonte, C. and Law, E.H., "Wheel-Rail Geometry Characterization," Department of Mechanical Engineering, Clemson University, Report No. TR-88-126-MEMMS, February, 1988

[7] Crowe, K.E. and Raj, P.K., "Analyses of Rail Chill Effect," Technology and Management Systems, Inc. Report No. DOT/FRA/ORD-96/xx, (in press).

[8] Shapiro, A.B., "TOPAZ2D - A Two-Dimensional Finite Element Code for Heat Transfer Analysis, Electrostatic, and Magnetostatic Problems," Lawrence Livermore National Laboratory, Livermore, CA. Report No. UCID-20824. July, 1986.

[9] Engelmann, B. and Hallquist, J.O., "NIKE2D - A Nonlinear, Implicit, Two-Dimensional Finite Element Code for Solid Mechanics," Lawrence Livermore National Laboratory, Livermore, CA. Report No. UCRL-MA-105413. April, 1991.

[10] Gordon, J., "Estimation of Residual Stresses in Railroad Car Wheels Resulting from Manufacture and Service Loading," MS Thesis, Department of Mechanical Engineering, Tufts University, February, 1998.

[11] Gordon, J.E. and Orringer, O., "Investigation of the Effects of Braking System Configurations on Thermal Input to Commuter Car Wheels," Volpe National Transportation Systems Center. Report No. DOT/FRA/ORD-96/01. March, 1996. 